\title{
UM CASO DE HIPERTROFIA BILATERAL EM QUELAS DE CARANGUEJO MACHO VIOLINISTA, MINUCA RAPAX (SMITH, 1870) (DECAPODA, BRACHYURA, OCYPODIDAE)
}

\author{
Queiroz, É.M.S. ${ }^{1,}$; Silva, L.N. ${ }^{2}$ \& Shinozaki Mendes, R. A. ${ }^{1}$ \\ ${ }^{1}$ Universidade Federal Rural de Pernambuco (UFRPE), Unidade Acadêmica de Serra Talhada (UAST), \\ Laboratório de Biologia Pesqueira (LAPEq). \\ ${ }^{2}$ Universidade Federal Rural de Pernambuco (UFRPE), Campus Recife. \\ *Autor correspondente: mirelly_e@hotmail.com
}

O presente estudo descreve a hipertrofia de quelipodos bilateral em um caranguejo macho violonista, Minuca rapax. A coleta ocorreu na área de manguezal próxima à cidade de Jaguaribe, localizada na porção norte da Ilha de Itamaracá, em Pernambuco, Brasil. Este espécime particular foi capturado manualmente em sua toca. Dentre os 126 indivíduos (48 femininos e 78 masculinos) do gênero Minuca sp. capturados, apenas este indivíduo apresentava quelipodos similares em tamanho e forma. Estes caranguejos apresentam um dos mais altos graus de dimorfismo sexual encontrados entre os decápodes. Os quelipodos podem ser mais propensos a desenvolver malformações devido à sua maior probabilidade de lesão por causa do comportamento de combate e sua queda durante os estágios finais do processo de muda. Algumas das causas de malformação em decapodas tem sido atribuídas a uma dupla geração de coordenação regenerativa não sincrônica na cicatrização de feridas. Devido à falta de estudos sobre a causa definitiva dessas anormalidades e deformações, mais investigações são necessárias para determinar os papéis dos indivíduos com anormalidades dentro das populações, bem como as principais causas dessas anormalidades.

Palavras-chave: quelipodos, anormalidade, decapoda. 